\title{
Sexuality and the drive for muscularity: Evidence of associations among British men
}

\author{
Viren Swami $^{\mathrm{a}, \mathrm{b}, *}$, Rachel Diwell ${ }^{\mathrm{a}}$, Donald R. McCreary ${ }^{\mathrm{c}, \mathrm{d}}$ \\ a Department of Psychology, University of Westminster, London, UK \\ ${ }^{\mathrm{b}}$ Department of Psychology, HELP University College, Kuala Lumpur, Malaysia \\ ' Department of Psychology, Brock University, St. Catharines, Ontario, Canada \\ d Department of Psychology, Carleton University, Ottawa, Ontario, Canada
}

\section{A R T I C L E I N F O}

Article history:

Received 5 May 2014

Received in revised form 13 August 2014

Accepted 15 August 2014

\section{Keywords:}

Drive for muscularity

Sociosexuality

Sexual assertiveness

Sexual sensation seeking

Sexuality

\begin{abstract}
A B S T R A C T
Previous studies have documented associations between sexuality and body image, but the directionality of this association is unclear among men. This study examined whether men's drive for muscularity can be considered a correlate of their sexuality. A community-based sample of 292 heterosexual men from London, UK, completed a survey consisting of measures of drive for muscularity, sociosexuality, sexual assertiveness, sexual esteem, and sexual sensation seeking. A multiple regression analysis showed that greater drive for muscularity was predicted by more unrestricted sociosexuality (i.e., a greater proclivity for short-term, transient relationships), greater sexual sensation seeking, and greater sexual assertiveness, once the effects of participant age and body mass index had been accounted for. Possible avenues for intervention based on a sex-positive approach are discussed in conclusion.
\end{abstract}

(C) 2014 Elsevier Ltd. All rights reserved.

\section{Introduction}

Studies consistently show that women are more likely to rate muscular male bodies as physically attractive (e.g., Dixson, Grimshaw, Ormsby, \& Dixson, 2014; Swami \& Tovée, 2005) and that possessing a muscular body is associated with greater mating success (Frederick \& Haselton, 2007). This, in turn, may engender a desire among men for greater muscularity, which is typically measured as drive for muscularity; that is, a desire to enhance one's musculature in order to reduce a perceived discrepancy between actual and ideal levels (McCreary \& Sasse, 2000). Studies have shown that men score higher than women on measures of drive for muscularity and higher scores among men are associated with negative health and psychological outcomes (for a review, see McCreary, 2012). While the centrality of muscularity for men's body image is undisputed, theoretical explanations for drive for muscularity have relied heavily on sociocultural models (McCreary, 2012). Recent work, on the other hand, has emphasised the importance of broader socio-political constructs in shaping men's drive for muscularity, including oppressive and patriarchal attitudes (Swami \&

\footnotetext{
* Corresponding author at: Department of Psychology, University of Westminster, 309 Regent Street, London W1B 2UW, UK. Tel.: +44 2079115000.

E-mail addresses: v.swami@westminster.ac.uk, virenswami@hotmail.com (V. Swami).
}

Voracek, 2013) and social dominance orientation (Swami et al., 2013).

Sexuality is another construct that may influence body image, but the available literature is limited by its focus on women (for a review, see Woertman \& van den Brink, 2012) and outcomefocused measures of men's sexual satisfaction (e.g., Daniel \& Bridges, 2013). That is, previous studies have adopted a perspective in which male sexuality is viewed as outcomes of body image, with an attendant focus on variables such as sexual functioning and satisfaction. However, there are reasons to think that men's sexuality may help to shape their drive for muscularity (see Vasilenko, Ram, \& Lefkowitz, 2011). For example, sexual prowess forms an important component of dominant stereotypes of masculinity: masculine men are expected to strive for autonomy, dominance, and aggressiveness, including in sexual relationships (Connell, 1995). The drive for muscularity is associated with several aspects of the male gender role, including male-typed traits and behaviours and more traditional gender-typed beliefs (McCreary, Saucier, \& Courtenay, 2005), allowing us to hypothesise that the desire to be more muscular should be correlated with sexual prowess. Another reason for a potential association between sexual prowess and the drive for muscularity stems from the possibility that stereotypes of men as sexual risk-takers and decision-makers contribute to a desire for greater muscularity. That is, to the extent that sexual prowess, alongside masculinity, is associated with muscularity, men may come to view the two as congruous. Although there is some 
evidence of a positive association between sexuality and men's drive for muscularity (Filiault, 2007), the relationship is usually framed in terms of sexuality as an outcome of men's body image.

With these issues in mind, we identified several sexualityrelated constructs that may be associated with men's muscularityoriented body image. First, sociosexuality refers to individual differences in people's inclination to engage in short-term or longterm sexual relationships (Gangestad \& Simpson, 1990). Being sexually restricted means displaying a propensity towards longterm, high-investment relationships with fewer people, whereas being sexually unrestricted means being open to more frequent, short-term, transient relationships without a need for commitment or intimacy. Previous work has shown that unrestricted men show a stronger preference for heteronormative female body types (e.g., lower body mass indices and waist-to-hip ratios; Swami, Miller, Furnham, Penke, \& Tovée, 2008) and have higher self-assessed attractiveness compared with restricted men (Weeden \& Sabini, 2007). Previous work has shown that unrestricted men are more likely than restricted men to emphasise their physical appearance (Rammsayer \& Troche, 2013); as such, we expected that men who are more unrestricted would show greater drive for muscularity.

We also identified sexual sensation seeking, which has been defined as "the propensity to attain optimal levels of sexual excitement and to engage in novel sexual experiences" (Kalichman et al., 1994, p. 387). Given the centrality of frequency and variety of intercourse to dominant stereotypes of masculine constructions of sexual encounters (Gillen, Lefkowitz, \& Shearer, 2006), we expected sexual sensation seeking to be associated with men's drive for muscularity. Finally, we included measures of sexual assertiveness (the tendency to be assertive about the sexual aspects of one's life) and sexual esteem (a positive regard for, and confidence in, the capacity to experience one's sexuality in a satisfying manner), with the expectation that men who scored higher on these traits would also show greater drive for muscularity.

\section{Method}

\section{Participants}

The participants were 292 heterosexual men recruited from the community in London, UK, of whom the majority were of British White ancestry (90.1\%). Participants ranged in age from 18 to 57 years $(M=28.55, S D=11.41)$ and in body mass index (BMI) based on self-reported height and weight from 19.15 to $32.15 \mathrm{~kg} / \mathrm{m}^{2}$ $(M=24.90, S D=4.51)$. In terms of educational qualifications, $32.2 \%$ had completed minimum secondary education, $16.1 \%$ were still in full-time education, $28.4 \%$ had an undergraduate degree, $4.1 \%$ had a postgraduate degree, and the remainder had some other qualification.

\section{Materials}

Drive for muscularity. Participants completed the Drive for Muscularity Scale (DMS; McCreary \& Sasse, 2000), which consists of 15 items measuring an individual's desire to have a more muscular body. Items were rated on a 6-point Likert-type scale ( $1=$ Always, $6=$ Never ) and were reverse-coded so that higher scores represent greater drive for muscularity. Scores on the DMS have been shown to have a two-factor lower-order structure in men (representing attitudinal and behavioural dimensions), but the two subscales also load onto a single higher-order dimension (McCreary, Karvinen, \& Davis, 2006). In the present work, the two subscales were strongly correlated $(r=.65)$. We therefore followed recent work in calculating a total DMS as the mean of all 15 items. McCreary (2007) reported that the total DMS score has good psychometric properties. In the present study, Cronbach's $\alpha$ for this measure was .90.
Sociosexuality. We measured sociosexual orientation using the Revised Sociosexual Orientation Inventory (SOI-R; Penke \& Asendorpf, 2008). This is a 9-item measure that examines dealing with past behavioural experiences, attitudes towards uncommitted sex, and sociosexual desire. All items were rated on 5-point scales and an overall score was computed as the sum of all items. A higher score on this measure reflects a more unrestricted sociosexual orientation, whereas a lower score reflects a more restricted orientation. Penke and Asendorpf (2008) provide evidence of good psychometric properties for this scale. Cronbach's $\alpha$ for the SOI-R in this study was .71.

Sexual sensation seeking. Participants completed the Sexual Sensation Seeking Scale (SSSS; Kalichman et al., 1994), an 11-item instrument that measures an individual's inclination to seek sexual excitement and to engage in novel sexual experiences. Items on the SSSS were rated on a 4-point Likert-type scale ( $1=$ Not at all like me, $4=$ Very much like me) and an overall mean score was computed. Higher scores on this scale reflect greater sexual sensation seeking. Scores on the scale have been shown to have good psychometric properties among heterosexual men (Gaither \& Sellborn, 2003). In the present study, Cronbach's $\alpha$ for this measure was .77.

Sexual assertiveness and esteem. Participants completed the Sexual Assertiveness and the Sexual Esteem subscales of the Multidimensional Sexuality Questionnaire (MSQ; Snell, Fisher, \& Walters, 1993). The former measures the tendency to be assertive in sexual aspects of one's life whereas the latter measures an individual's positive regard for, and confidence in, the capacity to experience their sexuality in a satisfying manner. Both subscales consist of 5 items, respectively, and were rated on 5-point Likerttype scales ( $1=$ Not at all characteristic of me, $5=$ Very characteristic of me). Mean scores were computed separately for each subscale (higher scores reflect greater sexual assertiveness or sexual esteem, respectively). Scores on these MSQ subscales have been shown to have good psychometric properties (Snell et al., 1993). In the present work, both subscales had good internal consistency: Sexual Assertiveness, $\alpha=.83$ and Sexual Esteem, $\alpha=.86$.

Demographics. Participants provided their demographic information consisting of age, ethnicity, educational qualifications, height, and weight. The latter two items were used to calculate participants' BMI $\left(\mathrm{kg} / \mathrm{m}^{2}\right)$. BMI was included as a proxy for actual muscle mass, as McCreary et al. (2006) showed a strong correlation between the two in a sample of university students.

\section{Procedure}

Ethics approval for this study was obtained from the relevant university ethics committee. Potential participants who fit study criteria (British residents of adult age and of exclusively heterosexual orientation) were invited to take part in a study on sexual relationships by four research assistants (two women, two men) trained in psychological methods. Recruitment was conducted opportunistically in sites of congregate activities (e.g., public parks, train stations, cultural venues, high streets) in Greater London. Recruitment took place through direct approaches by the research assistants on weekdays and attempts were made to minimise selection bias by sampling at different times of the day. Once participation had been agreed, participants provided written informed consent and completed an anonymous paper-and-pencil version of the survey in a quiet location set up for the purposes of the project in the vicinity of the catchment site. We randomised the order of presentation of the above scales, with the exception of demographic data, which always appeared last in the survey. All participants took part on a voluntary basis, were not remunerated for participation, and were provided with a debrief sheet upon completion of the survey. 
Table 1

Descriptive statistics and inter-scale bivariate correlations between all variables included in the present study.

\begin{tabular}{|c|c|c|c|c|c|c|c|}
\hline & (1) & (2) & (3) & (4) & (5) & (6) & (7) \\
\hline $\begin{array}{l}\text { (1) Drive for muscularity } \\
\text { (2) Sociosexual orientation } \\
\text { (3) Sexual sensation seeking } \\
\text { (4) Sexual esteem } \\
\text { (5) Sexual assertiveness } \\
\text { (6) Body mass index } \\
\text { (7) Age }\end{array}$ & & $.22^{* *}$ & $\begin{array}{l}.20^{*} \\
.48^{* *}\end{array}$ & $\begin{array}{l}.03 \\
.24^{* *} \\
.35^{* *}\end{array}$ & $\begin{array}{l}.12^{*} \\
.12^{*} \\
.28^{* *} \\
.46^{* *}\end{array}$ & $\begin{array}{r}.07 \\
.10 \\
-.05 \\
.07 \\
.01\end{array}$ & $\begin{array}{l}-.33^{* *} \\
-.16^{*} \\
-.28^{* *} \\
-.06 \\
.03 \\
.53^{* *}\end{array}$ \\
\hline $\begin{array}{l}M \\
S D\end{array}$ & $\begin{array}{l}2.53 \\
1.04\end{array}$ & $\begin{array}{r}25.55 \\
5.19\end{array}$ & $\begin{array}{l}2.65 \\
0.49\end{array}$ & $\begin{array}{l}3.58 \\
0.66\end{array}$ & $\begin{array}{l}3.01 \\
0.43\end{array}$ & $\begin{array}{r}24.90 \\
4.51\end{array}$ & $\begin{array}{l}28.55 \\
11.41\end{array}$ \\
\hline
\end{tabular}

Note: $N=292$.

${ }^{*} p<.05$.

** $p<.001$.

\section{Results}

Missing data comprised less than $2 \%$ of the total dataset and were replaced using the mean replacement technique. Descriptive statistics ( $M$ and $S D$ ) for, and bivariate correlations between, all variables included in the present study are reported in Table 1. As seen, greater drive for muscularity was significantly associated with more unrestricted sociosexual orientation, greater sexual sensation seeking, greater sexual assertiveness, and younger age. These correlations were generally of a small-to-medium effect size. Next, we computed a multiple linear regression with drive for muscularity as the criterion variable. Sociosexual orientation, sexual sensation seeking, sexual esteem, sexual assertiveness, BMI, and age were entered simultaneously as predictor variables into the multiple regression using the standard method. Multicollinearity diagnostics indicated that this was not a limiting issue (variance inflation factors reported in Table 2). The regression was significant, $F(6,291)=10.54, p<.001$, Adj. $R^{2}=.16$, with younger age, more unrestricted sociosexuality, greater sexual sensation seeking, higher BMI, and greater sexual assertiveness emerging as significant predictors. Regression coefficients and semi-partial correlations $\left(s r^{2}\right)$ are reported in Table 2 .

\section{Discussion}

Our results indicated firstly that - in consideration of the effects of age and participant BMI (which may be somewhat of a proxy for actual muscle mass) - men who were more sociosexually unrestricted (i.e., who were inclined to opt for more short-term, transient sexual relationships) had higher drive for muscularity. Previous research has shown that men who were more unrestricted were more likely to emphasise their physical attractiveness (Rammsayer \& Troche, 2013), which in turn may focus attention on any discrepancy between current and idealised muscularity. In addition, unrestricted men are known to have less liberal gender roles (Walker, Tokar, \& Fischer, 2000); having a preference for nonintimate sexuality may reinforce men's adherence to traditional gender roles or oppressive beliefs, which in turn are known to affect drive for muscularity (McCreary et al., 2005; Swami \& Voracek, 2013).
In addition, our findings showed that men's sexual sensation seeking and sexual assertiveness were positively associated with drive for muscularity. Although body image has been shown to predict sexual experiences, including assertiveness among women (Yamamiya, Cash, \& Thompson, 2006), the perspective we have adopted here suggests that men's drive for muscularity may be an outcome of sexuality. Of course, the cross-sectional design of our study means that the directionality of associations should be interpreted with care; nevertheless, it is possible that, to the extent that sexuality serves as a demonstration of adherence to dominant stereotypes masculinity, men who conform to stereotypes of sexual prowess (e.g., in terms of frequency and novelty of sexual experiences) may also seek to develop their musculature in line with cultural and gendered ideals in order to maximise the number and social desirability of the sexual partners. That is, men may desire greater muscularity precisely because they conform to gendered stereotypes of masculinity and sexuality.

Broadly speaking, our results highlight the importance of considering men's sexuality in relation to their drive for muscularity. An important question, however, concerns our view of men's sexuality as a precursor, rather than an outcome, of their body image. Part of the answer to this question relates to the measures of sexuality we have used; that is, we focused on measures of gendered sexuality, rather than sexual functioning or satisfaction. Beyond this, however, it is important to highlight the centrality of sexuality to definitions of dominant stereotypes of masculinity. For example, masculine sexual scripts prescribe that men be sexdriven (Connell, 1995), but may also focus attention on muscularity in constructions of sexualised bodies. In addition, recent longitudinal work indicated a positive change in men's body image following first sexual intercourse (Vasilenko et al., 2011), which supports our causational perspective. In short, muscles are experienced as important to a 'masculine' sex life.

As noted earlier, the correlational design of our study does mean that the direction of causation we are suggesting should be interpreted with caution. One way in which this issue could be investigated further would be through the use of a longitudinal design, which assesses the causational associations between men's sexuality and body image. Second, our study focused on direct relationships between sexuality and drive for muscularity, but it is quite

Table 2

Standardised and unstandardised regression coefficients for the multiple linear regression with drive for muscularity as the criterion variable.

\begin{tabular}{|c|c|c|c|c|c|c|c|}
\hline Predictor & $B$ & $S E$ & $\beta$ & $t$ & $p$ & $s r^{2}$ & VIF \\
\hline Sociosexual orientation & .04 & .01 & .19 & 3.03 & .003 & .026 & 1.33 \\
\hline Sexual sensation seeking & .41 & .15 & .17 & 2.80 & .006 & .022 & 1.32 \\
\hline Sexual esteem & .01 & .14 & .01 & 0.01 & .997 & $<.001$ & 1.47 \\
\hline Sexual assertiveness & .04 & .02 & .18 & 2.72 & .007 & .021 & 1.44 \\
\hline Body mass index & .20 & .10 & .13 & 2.03 & .044 & .012 & 1.40 \\
\hline Age & -.04 & .01 & -.41 & 6.09 & $<.001$ & .106 & 1.55 \\
\hline
\end{tabular}


possible that the uncovered relationships are mediated by additional variables not measured in the current work, such as sexist attitudes, adherence to traditional gender roles, attitudes towards media ideals of beauty, or use of pornography. In a similar vein, our understanding of these issues would benefit from attempts to adequately situate men's body image within theoretical frameworks that take into account the social, political, and economic context of men's corporeal experiences. Finally, replicating our results with more representative samples of the general population and in other cultural contexts would help establish the reliability of the uncovered associations.

Bearing in mind these limitations, a conservative conclusion is that men's sexuality plays a role in shaping their perceptions of socioculturally-constructed ideals of muscularity. Our findings highlight possible avenues for interventions aimed at reducing men's drive for muscularity. For example, a sex-positive approach that enshrines communication and acceptance of individual differences related to sexuality and sexual behaviour may be a useful step in attempts to reduce men's drive for muscularity. That is, a sex-positive approach may allow healthcare practitioners to better position themselves in order to resolve body image issues that are associated with men's sexuality.

\section{References}

Connell, R. W. (1995). Masculinities. Berkeley, CA: University of California Press.

Daniel, S., \& Bridges, S. K. (2013). The relationships among body image, masculinity, and sexual satisfaction in men. Psychology of Men and Masculinity, 14, 345-351. http://dx.doi.org/10.1037/a0029154

Dixson, B. J., Grimshaw, G. M., Ormsby, D. K., \& Dixson, A. F. (2014). Eye-tracking women's preferences for men's somatotypes. Evolution and Human Behavior, 35, 73-79. http://dx.doi.org/10.1016/j.evolhumbehav.2013.10.003

Filiault, S. (2007). Measuring up in the bedroom: Muscles, thinness, and men's sex lives. International Journal of Men's Health, 6, 127-142. http://dx.doi.org/10. 3149/jmh.0602.127

Frederick, D. A., \& Haselton, M. G. (2007). Why is muscularity sexy? Tests of the fitness indicator hypothesis. Personality and Social Psychology Bulletin, 33, 1167-1183. http://dx.doi.org/10.1177/0146167207303022

Gaither, G. A., \& Sellborn, M. (2003). The Sexual Sensation Seeking Scale: Reliability and validity within a heterosexual college student sample. Journal of Personality Assessment, 81, 157-167. http://dx.doi.org/10.1207/S15327752JPA8102. 0.7

Gangestad, S. W., \& Simpson, J. A. (1990). Toward an evolutionary history of female sociosexual variation. Journal of Personality, 58, 69-96. http://dx.doi.org/10. $1111 /$ j.1467-6494.1990.tb00908.x

Gillen, M. M., Lefkowitz, E. S., \& Shearer, C. L. (2006). Does body image play a role in risky sexual behavior and attitudes? Journal of Youth and Adolescence, 35 , 243-255. http://dx.doi.org/10.1007/s10964-005-9005-6

Kalichman, S. C., Johnson, J. R., Adair, V., Rompa, D., Multhauf, K., \& Kelly, J. A. (1994). Sexual sensation seeking: Scale development and predicting AIDS-risk behavior among homosexually active men. Journal of Personality Assessment, 62, 385-397. http://dx.doi.org/10.1207/s15327752jpa6203.1
McCreary, D. R. (2007). The Drive for Muscularity Scale: Description, psychometrics and research findings. In J. K. Thompson \& G. Cafri (Eds.), The muscularideal: Psychological, social, and medical perspectives (pp. 87-106). Washington, DC: American Psychological Association.

McCreary, D. R. (2012). Muscularity and body image. In T. F. Cash (Ed.), Encyclopedia of body image and human appearance (pp. 561-567). San Diego, CA: Academic Press.

McCreary, D. R., Karvinen, K., \& Davis, C. (2006). The relationship between the drive for muscularity and anthropometric measures of muscularity and adiposity. Body Image, 3, 145-152. http://dx.doi.org/10.1016/j.bodyim.2006.01.006

McCreary, D. R., \& Sasse, D. K. (2000). An exploration of the drive for muscularity in adolescent boys and girls. Journal of American College Health, 48, 297-304. http://dx.doi.org/10.1080/07448480009596271

McCreary, D. R., Saucier, D. M., \& Courtenay, W. H. (2005). The drive for muscularity and masculinity: Testing the associations among gender-role traits, behaviors, attitudes, and conflict. Psychology of Men and Masculinity, 6, 83-94. http://dx.doi.org/10.1037/1524-9220.6.2.83

Penke, L., \& Asendorpf, J. B. (2008). Beyond global sociosexual orientations: A more differentiated look at sociosexuality and its effects on courtship and romantic relationships. Journal of Personality and Social Psychology, 95, 1113-1135. http://dx.doi.org/10.1037/0022-3514.95.5.1113

Rammsayer, T. H., \& Troche, S. J. (2013). The relationship between sociosexuality and aspects of body image in men and women: A structural equation modeling approach. Archives of Sexual Behavior, 42, 1173-1179. http://dx.doi.org/10. 1007/s10508-013-0114-0

Snell, W. E., Jr., Fisher, T. D., \& Walters, A. S. (1993). The Multidimensiona Sexuality Questionnaire: An objective self-report measure of psychological tendencies associated with human sexuality. Annals of Sex Research, 6, 27-55. http://dx.doi.org/10.1007/BF00849744

Swami, V., Miller, R., Furnham, A., Penke, L., \& Tovée, M. J. (2008). The influence of men's sexual strategies on perceptions of women's bodily attractiveness health, and fertility. Personality and Individual Differences, 44, 98-107. http://dx. doi.org/10.1016/j.paid.2007.07.017

Swami, V., Neofytou, R.-V., Jablonska, J., Thirlwell, H., Taylor, D., \& McCreary D. R. (2013). Social dominance orientation predicts drive for muscularity among British men. Body Image, 10, 653-656. http://dx.doi.org/10. 1016/j.bodyim.2013.07.007

Swami, V., \& Tovée, M. J. (2005). Male physical attractiveness in Britain and Malaysia: A cross-cultural study. Body Image, 2, 383-393. http://dx.doi.org/10. 1016/j.bodyim.2005.08.001

Swami, V., \& Voracek, M. (2013). Associations among men's sexist attitudes, objectification of women, and their own drive for muscularity. Psychology of Men and Masculinity, 14, 168-174. http://dx.doi.org/10.1037/a0028437

Vasilenko, S. A., Ram, N., \& Lefkowitz, E. S. (2011). Body image and first sexual intercourse in late adolescents. Journal of Adolescence, 34, 327-335. http://dx.doi.org/10.1016/j.adolescence.2010.04.005

Walker, D. F., Tokar, D. M., \& Fischer, A. R. (2000). What are eight popular masculinity-related instruments measuring? Underlying dimensions and their relations to sociosexuality. Psychology of Men and Masculinity, 1, 98-108. http://dx.doi.org/10.1037/1524-9220.1.2.98, pii:S152492200200021X

Weeden, J., \& Sabini, J. (2007). Subjective and objective measures of attractiveness and their relation to sexual behavior and sexual attitudes in university students. Archives of Sexual Behavior, 36, 79-88. http://dx.doi.org/10. 1007/s10508-006-9075-x

Woertman, L., \& van den Brink, F. (2012). Body image and female sexua functioning and behavior: A review. Journal of Sex Research, 49, 184-211. http://dx.doi.org/10.1080/00224499.2012.658586

Yamamiya, Y., Cash, T. F., \& Thompson, J. K. (2006). Sexual experiences among college women: The differential effects of general versus contextual body images on sexuality. Sex Roles, 55, 421-427. http://dx.doi.org/10.1007/s11199-006-9096-x 